\title{
Insect Biochemistry Goes to School .
}

Leonardo R.Cunha, Cecília Cudischevitch, Willy Jablonka, Alan Brito, and Mário A. Silva-Neto

\section{Laboratório de Sinalização Celular, IBqM-UFRJ}

Many arthropods feed on vertebrate blood and eventually transmit diseases to the human being. Ordinary citizens are continuously exposed to vectors of major diseases and thus prone to contamination. In the present study we have evaluated a new approach regarding the basic biochemistry mechanism that regulates the biology of Triatominaes, well known as vectors of Chagas Disease. We have used a comic book "Carlos Chagas: 100 years of the discovery of a hero", produced by researchers at our laboratory. The main concepts presented include: neurochemistry of insect olfaction, hemostasis, blood digestion, redox balance to mention some. The material was applied between 60 pupils of the seventh year of elementary school. The work is divided into two phases: an assessment of the concepts that the students bring their experiences into the classroom by producing conceptual maps followed by the intervention with the comic and production of new conceptual maps under the influence of activity with the material. Analysis of 18 conceptual maps obtained from 06 different groups at three different points revealed that the average score 07 at the beginning of the evaluation went to an average of 45 at the end of the study. This result suggests that a change in the approach of content can give encouragement to students to better develop the theme of contributing to a proper process of conceptual change.

Supported by FAPERJ. 
This document was created with Win2PDF available at http://www.win2pdf.com. The unregistered version of Win2PDF is for evaluation or non-commercial use only. This page will not be added after purchasing Win2PDF. 